\section{Carbon isotope}

\section{evidence for early life}

The Letter by Mojzsis et al. ${ }^{1}$ on evidence for life on Earth before 3,800 million years ago was accompanied by a discussion of the effects of prograde thermal metamorphism on carbon isotope ratios. This discussion included an analysis of the effect a Rayleigh distillation process might have in reducing the ${ }^{13} \mathrm{C} /{ }^{12} \mathrm{C}$ ratio of organic carbon that is residual to oxidation during diagenesis and metamorphism. The calculations presented in that discussion (including Fig. 3, its caption and text on page 58 of ref. 1) contained errors that contributed to the conclusion that it would have been physically impossible for such a process to produce the observed $\delta^{13} \mathrm{C}$ values of approximately $-35 \%$ (with respect to the PDB standard) from initial abiotic values of $-10 \%$. Here we correct those errors and discuss the significance of the correct calculation.

Two related errors are present in the Rayleigh distillation calculation as published in ref. 1. First, the Rayleigh equation in the caption of Fig. 3 uses $\delta^{13} \mathrm{C}$ values where ${ }^{13} \mathrm{C} /{ }^{12} \mathrm{C}$ ratios should be used. Second, the direction of the equilibrium isotopic fractionation between $\mathrm{CO}_{2}$ and graphite is opposite to that necessary for the use of the Rayleigh equation as it is commonly derived for stable isotopes, and its absolute magnitude differs substantially from that estimated by experimental studies. The correct form of the Rayleigh equation for the distillation of $\mathrm{CO}_{2}$ from residual graphite is:

$$
R_{\mathrm{f}}=R_{\mathrm{i}} \times F^{(\alpha-1)}
$$

where $R_{\mathrm{i}}$ is the isotope ratio ${ }^{13} \mathrm{C} /{ }^{12} \mathrm{C}$ in the graphite before oxidation and distillation of $\mathrm{CO}_{2}, R_{\mathrm{f}}$ is the same ratio in the residual graphite after this reaction, $F$ is the mole fraction of the residual phase (graphite) remaining after this reaction and $\alpha$ is the equilibrium isotope fractionation factor between the evolved $\mathrm{CO}_{2}$ and residual graphite at any given step in the Rayleigh distillation process, defined as $\alpha=R_{\mathrm{CO}_{2}} / R_{\text {graphite }}$ (ref. 2). Translation of equation (1) into standard $\delta$ notation yields:

$$
\delta_{\mathrm{f}}=\left(1000 \times\left(F^{(\alpha-1)}-1\right)\right)+\delta_{\mathrm{i}} F^{(\alpha-1)}
$$

where $\delta$ values are defined by the equation:

$$
\delta=\left(R / R_{\text {std }}-1\right) \times 1000
$$

with $R_{\text {std }}$ being the ${ }^{13} \mathrm{C} /{ }^{12} \mathrm{C}$ ratio of a reference standard (for example PDB).

The correct value for $\alpha$ $\left(\mathrm{CO}_{2}\right.$ - graphite) at $400{ }^{\circ} \mathrm{C}$, the temperature appropriate for modelling prograde metamorphism of the samples in question, is 1.0111 (ref. 3), corresponding to an $11 \%$ difference in $\delta^{13} \mathrm{C}$ between $\mathrm{CO}_{2}$ and graphite. Using this value for $\alpha$, an initial $\delta^{13} \mathrm{C}$ value of $-10 \% 0_{\mathrm{PDB}}$ (the lower limit of 'abiotic' carbon from ref. 1), and equation (2), a $\delta^{13} \mathrm{C}$ value of $-35 \%$ in residual graphite are obtained when $F=0.1(10 \%$ of the original carbon remains in the rock as graphite), substantially different from the value of $F=2.5 \times 10^{-11}$ estimated by Mojzsis et al. ${ }^{1}$.

It was argued in ref. 1 that the extreme value of $F$ that was calculated disproved the possibility that low $\delta^{13} \mathrm{C}$ was the result of oxidation during metamorphism because virtually no carbon would remain in the rock. The correct value for $F=0.1$ ( $90 \%$ reaction) is not sufficiently extreme to rule out the possibility, and instead the calculation permits that, under the assumed conditions, the oxidation of carbonaceous matter during metamorphism could produce residual graphite with $\delta^{13} \mathrm{C}$ values in the range that is often regarded as diagnostic of biogenic carbon (less than $-20 \%$ ).

The debate over the carbon-isotope shifts that are expected to accompany diagenesis and metamorphism of carbonaceous matter is old (for example, refs 4,5 ), and controversy as to the origin and initial isotopic composition of carbon in Archean rocks continues ${ }^{6}$. Resolving this issue for a given sample requires that the action of oxidation reactions that proceed by Rayleigh distillation during hydrocarbon maturation and metamorphism is proved or disproved. The requirements for such a process to lead to low $\delta^{13} \mathrm{C}$ residual carbon are that fluids in equilibrium with residual hydrocarbons and/or graphite must have a high ratio of $\mathrm{CO}_{2} / \mathrm{CH}_{4}$, and that isotopic exchange between residual hydrocarbons and/or graphite and fluids must be rapid. Under common oxygen fugacity $\left(f_{\mathrm{O}_{2}}\right)$ conditions and mid-crustal pressures, and at temperatures less than $500{ }^{\circ} \mathrm{C}, \mathrm{C}-\mathrm{O}-\mathrm{H}$ fluids are generally $\mathrm{CH}_{4}$ dominated ${ }^{7}$. Thus, these requirements are not expected to be met unless metamorphic conditions are unusually oxidizing or if temperatures are higher ${ }^{7}$.

A number of previous studies have demonstrated that metamorphism of carbonaceous matter in sedimentary rocks commonly leads to increases, rather than decreases, in $\delta^{13} \mathrm{C}$ owing to the distillation of $\mathrm{CH}_{4}$ and exchange with high $\delta^{13} \mathrm{C}$ carbonate minerals ${ }^{8,9}$. Armouring of carbonaceous matter by crystals of a C-poor phase, such as is the case for the graphite analysed by Mojzsis et al. ${ }^{1}$, would tend further to reduce the opportunities for isotope fractionation during metamorphism ${ }^{10}$. For these reasons the authors of the original paper $^{1}$ support the initial interpretation that measured values of $\delta^{13} \mathrm{C}$ in graphite define maximum limits on the initial $\delta^{13} \mathrm{C}$ values of precursor carbonaceous matter.

\section{J. M. Eiler}

Division of Geological and Planetary Sciences, California Institute of Technology,

Mail code 170-25, Pasadena,

California 91125, USA

e-mail: eiler@expet.gps.caltech.edu

\section{S. J. Mojzsis, G. Arrhenius}

Scripps Institution of Oceanography,

University of California at San Diego,

La Jolla, California 92093-0220, USA

\footnotetext{
1. Mojzsis, S. J. et al. Nature 384, 55-59 (1996).

2. Epstein, S. Researches in Geochemistry (ed. Abelson, P. H.) 217-240 (1959)

3. Chacko, T., Mayeda, T. K., Clayton, R. N. \& Goldsmith, J. R. Geochim. Cosmochim. Acta 55, 2867-2882 (1991).

4. Rankama, K. Geochim. Cosmochim. Acta 5, 142-152 (1954).

5. Craig, H. Geochim. Cosmochim. Acta 6, 186-196 (1954).

6. Naraoka, H., Ohtake, M., Maruyama, S. \& Ohmoto, H. Chem. Geol. 133, 251-260 (1996).

7. Holloway, J. R. in Fluid Inclusions: Applications to Petrology (eds Hollister, L. S. \& Crawford, L. M.) 13-38 (Mineral. Assoc. Canada, Calgary, 1981).

8. McKirdy, D. M. \& Powell, T. G. Geology 2, 591-595 (1974).

9. Peters, K. E., Rohrback, B. G. \& Kaplan, I. R. Bull. Am. Assoc. Petrol. Geol. 65, 501-508 (1981).

10. Dunn, S. R. \& Valley, J. W. J. Metamorph. Geol. 10, 487-501 (1992).
}

\section{Clouds, precipitation and temperature range}

The daily range of surface air temperature has decreased worldwide since the 1950s, with an increase in night-time minimum temperature $\left(T_{\min }\right)$ exceeding the increase in daytime maximum temperature $\left(T_{\max }\right)^{1-3}$. Coincident increases in total cloud cover found in many locations ${ }^{1}$ have been cited as a plausible cause $e^{1,4,5}$. Clouds have a damping effect on diurnal temperature range (DTR), aiding cooling of the Earth's surface by reflecting sunlight and heating the surface by increasing downward longwave radiation, as confirmed by model studies ${ }^{6,7}$. Increasing aerosol concentrations have been suggested as a possible cause of the observed increase in cloudiness ${ }^{4}$, but we suggest that greenhouse gas-induced increases in thick precipitating clouds and precipitation are better candidates to explain the decrease in DTR.

DTR has been negatively correlated with both total cloud cover and precipitation throughout this century, over all regions for which data are available (Fig. 1). In particular, the correlation is remarkable for the long-term trends, especially over mid-latitude Canada and Australia. Available surface and ship observations ${ }^{8}$ indicate that, during the 1952-81 period, cumulonimbus, nimbostratus and cirriform clouds increased substantially over Australia, Europe and the United States, but there was little change in low-altitude cumulus and stratus clouds over northern mid-latitude oceans. Consistent 